\title{
РИСКИ НАХОЖДЕНИЯ АВТОМОБИЛЕЙ НА ДОРОГАХ В ЗОНЕ РАСПОЛОЖЕНИЯ АВТОЗАПРАВОЧНЫХ СТАНЦИЙ. РЕКОМЕНДАЦИИ ПО РАЗМЕЩЕНИЮ АЗС
}

\begin{abstract}
Одной из важнейших составляющих комплексного обслуживания на автомобильных дорогах является автозаправочная станция. Автозаправочные станции отнесены к объектам, которые представляют повышенную опасность. Эта опасность связана с последствиями деятельности АЗС и аварий на них. На участках дорог, где расположены АЗС, концентрация вредных выбросов в атмосферу резко увеличивается. В случае аварии (например, взрыва) загрязнение может сильно превышать критические нормы, это приведет также к задержке движения на дороге, разрушениям сооружений и в результате к большим экономическим затратам на ликвидацию последствий аварии. Сегодня размещение автозаправочных станций не учитывает возможные аварийные ситуации, когда легковоспламеняющиеся вещества могут попасть из оборудования в окружающую среду и создать реальную возможность пожаров и взрывов топливовоздушных смесей. Основным параметром определения безопасного расстояния от АЗС является ее взрывоопасность. В случае аварии на станции возможен взрыв паров пролитого топлива с избыточным давлением взрывной волны, в зоне здания, сооружения и транспортные средства могут испытать сильные и средние разрушения, и вызвать травмы для людей. Последствия такой аварии будут зависеть от количества автомобилей, сооружений и, соответственно, людей, попавших в зону поражения, а также силы взрыва. Поэтому вопрос безопасных расстояний до автомобильной дороги и мест массового скопления людей остается открытым и острым.
\end{abstract}

Ключевые слова: Автозаправочная станция, взрыв, ударная волна, избыточное давление взрывной волны.

Взрыв - быстрое экзотермическое химическое превращение взрывоопасной среды, сопровождающееся выделением энергии и образованием сжатых газов, способных выполнять работу. При взрыве образуется ударная волна, которая создает избыточное давление, вызывает разрушительные последствия.

При случайном разливе топлива на определенную площадь, горючие вещества начинают испаряться, образуя топливовоздушные смеси, которые при благоприятных условиях могут взорваться. Благоприятными условиями для такого случая будет считаться скорость ветра до 0,5 м/с, температура окружающей среды $\approx$ $+10^{\circ} \mathrm{C}$ и разлив топлива с более высоким октановым числом. Радиус действия

\footnotetext{
1 Тютюнник Яна, аспирантка, ассистент кафедры проетирование автомобильных дорог, геодезии и землеустройства, Национального транспортного университета, ул. Суворова, 1, г. Киев, 01010, Украина, asia_t@ukr.net
} 
взрывной волны будет зависеть от этих факторов, и его разрушительная сила будет отличаться на разных расстояниях от эпицентра взрыва.

В зависимости от избыточного давления возникают различные повреждения у людей и животных, которые по сложности поражения подразделяются на легкие, средние и очень тяжелые. Легкие травмы возникают при избыточном давлении 2040 кПа (0,2 - 0,4 кгс/см2) и характеризуются вывихами временным повреждением слуха, контузией. Средние травмы возникают при избыточном давлении 40-60 кПа (0,4-0,6 кгс/см2) и оказываются в контузии, повреждении органов слуха, вывихах конечностей, кровотечению из носа и ушей, разрывах барабанных перепонок. Тяжелые травмы возникают при избыточном давлении 60-100 кПа (0,6-1 кгс/см²) и характеризуются тяжелыми контузиями, переломами конечностей, часто открытыми, сильными кровотечениями из носа и ушей. Очень тяжелые травмы возникают при избыточном давлении более 100 кПа (более 1 кгс/см²), для них характерны переломы костей, разрывы внутренних органов (печени, селезенки, почек, легких и других), открытые переломы конечностей, сотрясения мозга, переломы позвоночника.

Но большинство травм у человека может возникнуть от обломков разрушенных сооружений или транспортных средств, возможны также ожоги от горения пролитого топлива.

Избыточное давление для разрушения различных конструкций зависит от материалов, из которых они изготовлены:

- Сооружения: железобетонные и антисейсмические конструкции - 50-80 кПа;

- Кирпичные дома - 30-40 кПа;

- Деревянные дома - 10-20 кПа;

- Стекло - 6-8 кПа.

В зоне сильных разрушений избыточное давление составляет от 50 до 30 кПа. Разрушения характеризуются деформацией большей части несущих конструкций, могут оставаться частично стены и перекрытия нижних этажей, образуются завалы. Они возникают при таких избыточных давлениях:

- Многоэтажных домов - 25-30 кПа,

- Малоэтажных зданий - 25-35 кПа,

- Сооружений производственного типа - 30-50 кПа.

В этой зоне автомобиль может быть полностью разрушен, что нанесет очень тяжелые поражения водителю и пассажирам.

В зоне средних разрушений большинство несущих конструкций сохраняется, но частично деформируется. Сохраняется основная часть стен с возможными трещинами в наружных стенах и провалами в отдельных местах, но при этом второстепенные стены и часть несущих конструкций могут быть разрушены полностью. Герметичные убежища не повреждаются. Средние разрушения несут:

- Многоэтажные сооружения при избыточном давлении 10-20 кПа,

- Малоэтажные здания - 15-25 кПа,

- Производственные сооружения - 20-30 кПа.

На коммунально-энергетической сети деформируются и разрушаются отдельные опоры воздушных линий электропередачи, повреждаются технологические трубопроводы. Транспортное средство может быть опрокинуто ударной волной со всеми выходящими из этого последствиями. 
В зоне слабых разрушений разрушаются окна, двери, легкие перегородки, появляются трещины, в основном, в стенах верхних этажей. Подвалы и нижние этажи сохраняются. Незначительные разрушения и повреждения возникают на коммунально-энергетической сети. Слабые разрушения зданий всех типов возникают при избыточном давлении 7-20 кПа. характеризуются нарушением самых слабых элементов зданий: карнизов, перегородок, дверей, окон и др. В автомобилях, по меньшей мере, разрушаются окна. Повреждение зданий всех типов, которые возникают при избыточном давлении 3-5 кПа, характеризуются нарушением самых слабых элементов зданий: карнизов, перегородок, дверей, окон и др.

Избыточное давление $\Delta$ Рф для сферической воздушной ударной волны, свободно распространяется, убывая по мере удаления от места взрыва. Поэтому расчет его значений обычно проводится на основании соотношений, в которых давление является функцией двух аргументов - массы ВР и расстояния от места взрыва.

Скорость спада значения $\Delta$ Рф взрыва изменяется за счет воздействия на ударную волну среды, в которой она распространяется. Чем больше расстояние от места взрыва, тем сильнее искажается характер изменения давления во фронте ударной волны.

При взрыве газо-воздушной смеси (ГПС) образуется очаг взрыва, ударные волны которого способны вызвать весьма большие разрушения на строительных объектах.

В наземном взрыве ГПС принято выделять три полусферические зоны в надземном пространстве (рис. 1) и зону сейсмического эффекта взрыва. Здания и сооружения могут получить повреждения от:

1) детонационной волны;

2) разлета осколков и продуктов взрыва;

3) воздействия ударной волны;

4) сейсмического эффекта взрыва..

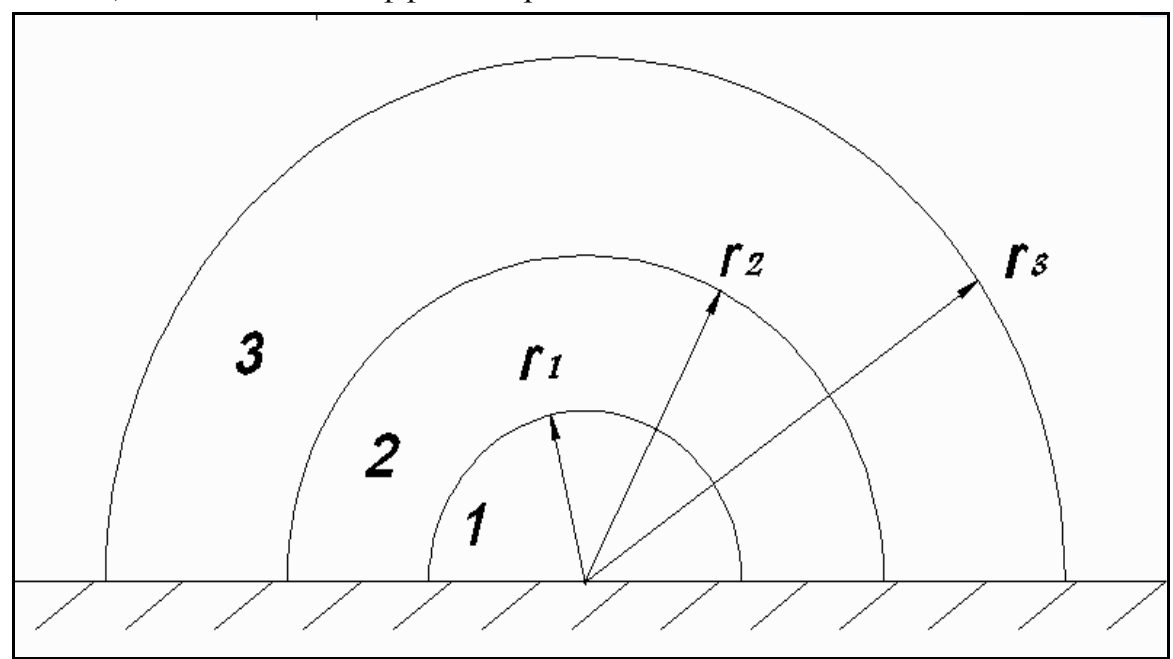

Рисунок 1. Зоны организации взрыва ВР:

1 - зона детонационной волны, rl; 2 - действия продуктов взрыва, r2; 3 - воздушной взрывной волны, r3. 
1) Влияние детонационной волны.

Зону детонационной волны можно рассматривать в пределах газового облака взрыва, где $\mathrm{r}<\mathrm{r} 1$. При взрывах газовоздушных смесей параметры внутри газового облака могут меняться в очень широких пределах в зависимости от условий взрыва, концентрации горючей компоненты и характера взрывного горения, которые при прогнозировании взрывов, особенно на открытом воздухе, учесть практически невозможно. Поэтому обычно расчеты проводят для худшего случая, при котором разрушительные последствия взрыва наибольшие.

Таким наихудшим случаем является детонационное горение смеси стехиометрического состава. Скорость распространения процесса детонационного горения внутри облака очень большая и превышает скорость звука. Однако для проведения приближенной оценки параметров взрыва можно условно принять, что облако имеет форму полусферы с центром на поверхности земли, взрыв ГПС происходит мгновенно и давление в процессе взрыва одинаково и постоянно во всех точках, находящихся в середине облака.

Для большинства углеводородных смесей стехиометрического состава можно принять, что давление внутри газового облака составляет 1700 кПа.

Радиус зоны детонационной волны $\mathrm{rl}$, м, для наиболее часто используемых углеводородов можно приблизительно рассчитывать по эмпирической формуле:

$$
\mathrm{r}_{1}=17,5 \times \sqrt[3]{\delta \cdot \mathrm{M}_{\mathrm{XP}}}
$$

где: Мхр - масса вещества, которая находилась в объеме до аварии (до взрыва), кг;

$\delta$ - коэффициент, зависящий от способа хранения вещества, показывающий долю вещества, переходную при аварии в газ:

$\delta=1$ - для газов при атмосферном давлении;

$\delta=0,5 \ldots 0,6$ - для сжиженных газов, хранящихся под давлением;

$\delta=0,1$ - для сжиженных газов, хранящихся изотермически;

$\delta=0,02 \ldots 0,07$ - для разлитых легковоспламеняющихся веществ (ЛВЖ).

2) Влияние разлета продуктов взрыва.

Радиус зоны действия продуктов взрыва ГПС, которые способны повредить строительные объекты r2, м, рассчитывается по эмпирической формуле:

$$
\mathrm{r}_{2}=1,7 \times \mathbf{r}_{1}
$$

3) Влияние взрывных волн на расстояниях $r>r 1$.

Именно 3 зона и является основной для решения поставленных задач в данном исследовании для расчета радиуса действия избыточного давления на фронте ударной волны.

При случайном разливе топлива на определенную площадь, горючие вещества начинают испаряться, образуя топливовоздушные смеси, которые при благоприятных условиях могут взорваться. Используя НАПБ Б.03.002-2007 «Нормы определения категорий помещений, зданий и наружных установок по взрывопожарной и пожарной опасности» [3], Методику определения рисков и 
приемлемых уровней для декларирования безопасности объектов повышенной опасности [4] и ряд других источников [7-12], были получены формулы для расчета избыточного давления во фронте ударной волны при сгорании парогазовых облаков в открытом пространстве:

$$
\Delta P=P_{0} \cdot\left(0,8 m_{п р}^{0,33} / r+3 m_{п р}^{0,66} / r^{2}+5 m_{\text {пр }} / r^{3}\right)
$$

где, $\Delta P$ - избыточное давление во фронте ударной волны, кПа;

$P_{0}$ - атмосферное давление, кПа (допускается принимать равным 101 кПа);

$r$ - расстояние от геометрического центра газовоздушной облака, м;

$m_{\text {пр }}$ - приведенная масса газа или пара, кг, рассчитана по формуле:

$$
m_{\text {пр }}=\left(Q_{\text {зг }} / Q_{0}\right) \cdot m \cdot Z
$$

где $Q_{3 г}$ - удельная теплота сгорания газа или пара, Дж / кг;

$Z$ - коэффициент участия во взрыве (в расчетах принят 0,1 );

$Q_{0}$ - константа (теплота сгорания тротила), равная 4,52-106 Дж / кг;

$m$ - масса горючих газов и (или) пары, поступившей в результате аварии в окружающее пространство, кг.

Импульс волны давления $i$, Па / с, рассчитывают по формуле:

$$
i=123 \cdot m_{\text {пр }}^{0,66} / r
$$

Результаты расчетов для газа (пропан-бутан) и бензина при случайном разливе и образовании топливовоздушной смеси над зеркалом разлива приведены в таблицах 1 и 2.

Таблица 1. Избыточное давление на фронте ударной волны облака топливовоздушной смеси на открытом пространстве при разрушении резервуара и площади разлива $100 \mathrm{~m}^{2}$, кПа.

\begin{tabular}{|c|c|c|c|c|c|}
\hline \multirow{2}{*}{$\begin{array}{c}\text { Емкость } \\
\text { резервуара }\end{array}$} & \multirow{2}{*}{$\begin{array}{c}\text { Наименование } \\
\text { вещества }\end{array}$} & \multicolumn{5}{|c|}{ Избыточное давление на фронте взрывной } \\
& & $250 л$ & $50 \mathrm{M}$ & $75 \mathrm{M}$ & $100 \mathrm{M}$ \\
\cline { 3 - 6 } & пропан-бутан & 191 & 49 & 25 & 16 \\
\hline 10 & пропан-бутан & 191 & 49 & 25 & 16 \\
\hline 7,5 & пропан-бутан & 191 & 49 & 25 & 16 \\
\hline 5 & Бензин А-95 & 53,95 & 17,62 & 10,05 & 6,96 \\
\hline 10 & Бензин А-98 & 60,39 & 19,31 & 10,91 & 7,52 \\
\hline 10 & \multicolumn{5}{|c}{} \\
\hline
\end{tabular}


Таблица 2. Импульс волны давления взрыва облака топливо-воздушной смеси на открытом пространстве при разрушении резервуара и площади разлива $100 \mathrm{M} 2$, Па / c.

\begin{tabular}{|c|c|c|c|c|c|}
\hline Емкость & Наименование & \multicolumn{4}{|c|}{ Импульс волны давления, Па / с } \\
\cline { 3 - 6 } резервуара & вещества & $25 \mathrm{M}$ & $50 \mathrm{M}$ & $75 \mathrm{M}$ & $100 \mathrm{M}$ \\
\hline 10 & пропан-бутан & 797 & 398 & 265 & 199 \\
\hline 7,5 & пропан-бутан & 797 & 398 & 265 & 199 \\
\hline 5 & пропан-бутан & 797 & 398 & 265 & 199 \\
\hline 10 & Бензин А-95 & 221,94 & 110,97 & 73,98 & 55,49 \\
\hline 10 & Бензин А-98 & 251,31 & 125,65 & 83,77 & 62,83 \\
\hline
\end{tabular}

Как видно в таблицах 1 и 2 по результатам расчетов объем пролитого топлива никакой роли не играет. Так как количество вещества, испарившееся с поверхности разлива, будет зависеть от площади пролива и внешних факторов, таких как температура воздуха, скорость воздуха над топливом и его вид (октановое число бензина, дизтопливо, газ), которые повлияют на скорость испарения.

По результатам расчетов было установлено, что радиус действия избыточного давления в фронте ударной волны дизтоплива чрезвычайно мал по сравнению с бензином, по этому далее рассматривается только бензины марок А-95 и А-98. Результаты расчетов приведены в таблице 3.

Таблица 3. Радиус действия избыточного давления в фронте ударной волны топливовоздушной смеси в зависимости от площади разлива топлива при скорости ветра 0,5 м / с и температуре окружающей среды $10^{\circ} \mathrm{C}$.

\begin{tabular}{|c|c|c|c|c|c|c|}
\hline $\begin{array}{c}\text { Площадь } \\
\text { разлива, м }{ }^{2}\end{array}$ & $\begin{array}{c}\mathrm{P}=14 \kappa \Pi а \\
\text { А-95 }\end{array}$ & $\begin{array}{c}\mathrm{P}=14 \kappa П а \\
\text { А-98 }\end{array}$ & $\begin{array}{c}\mathrm{P}=28 \kappa \Pi а \\
\text { A-95 }\end{array}$ & $\begin{array}{c}\text { Р=28кПа } \\
\text { А-98 }\end{array}$ & $\begin{array}{c}\mathrm{P}=70 \text { кПа } \\
\text { А-95 }\end{array}$ & $\begin{array}{c}\text { P=70кПа } \\
\text { А-98 }\end{array}$ \\
\hline 50 & 117,1 & 133,1 & 40,1 & 45,6 & 23,4 & 26,6 \\
\hline 100 & 183,6 & 207,9 & 63 & 71,3 & 36,7 & 41,6 \\
\hline 150 & 236,6 & 266 & 81,1 & 91,2 & 47,3 & 53,2 \\
\hline
\end{tabular}




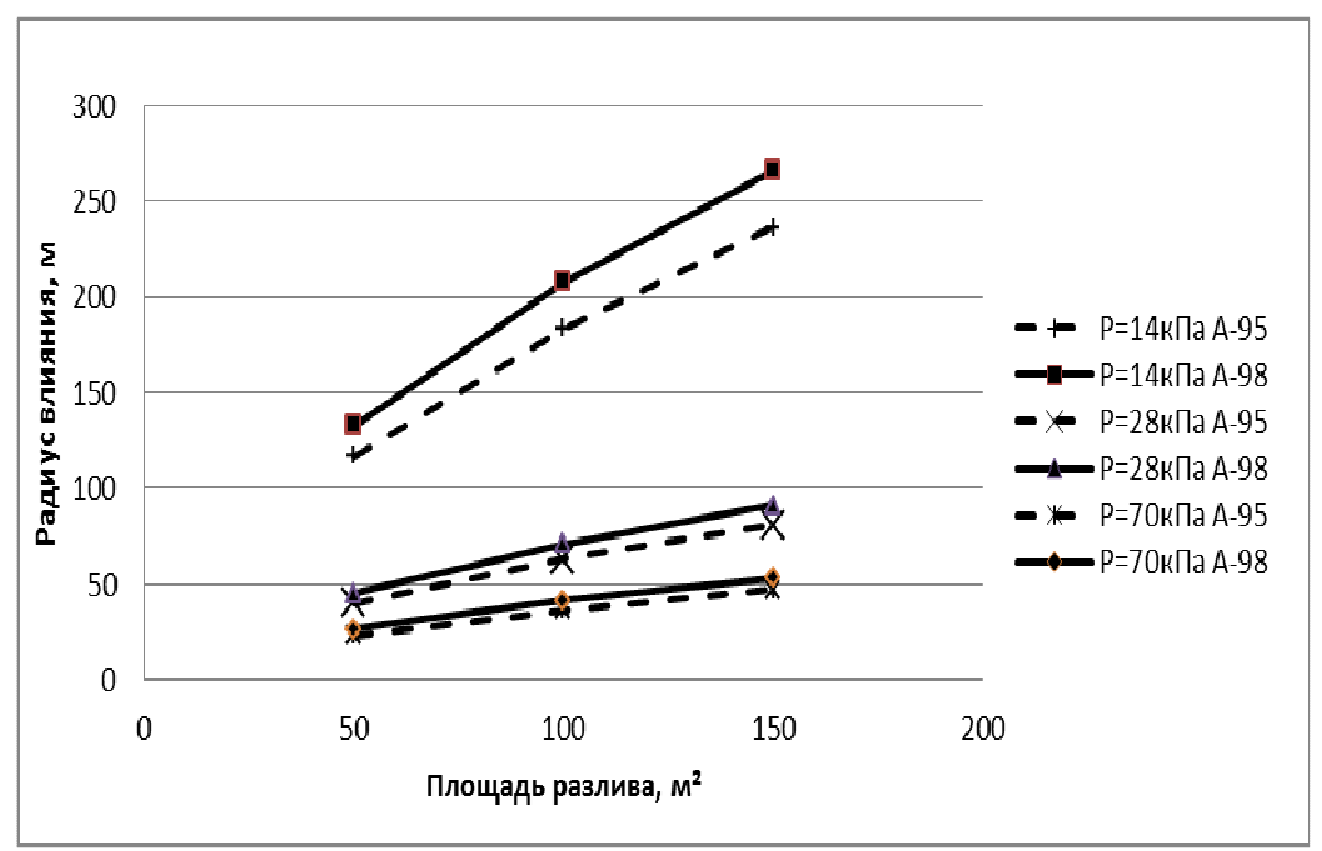

Рисунок 2. Зависимость радиуса действия избыточного давления $(14,28$ и 70 кПа) на фронте взрывной волны топливовоздушной смеси от площади разлива при скорости ветра 0,5 м / с и температуре окружающей среды $10^{\circ} \mathrm{C}$.

В случае повреждения ТРК площадь разлива топлива составит до 100 м $^{2}$. На рисунке 2 показано, какие здания и какая длина участка дороги, попадают в зону сильных, средних и слабых разрушений. Здание АЗС попадает в зону сильных разрушений (от 70 кПа), 122 м дороги находятся в зоне сильных и средних, а 244 м (366 - 122) - средних и слабых разрушений. 


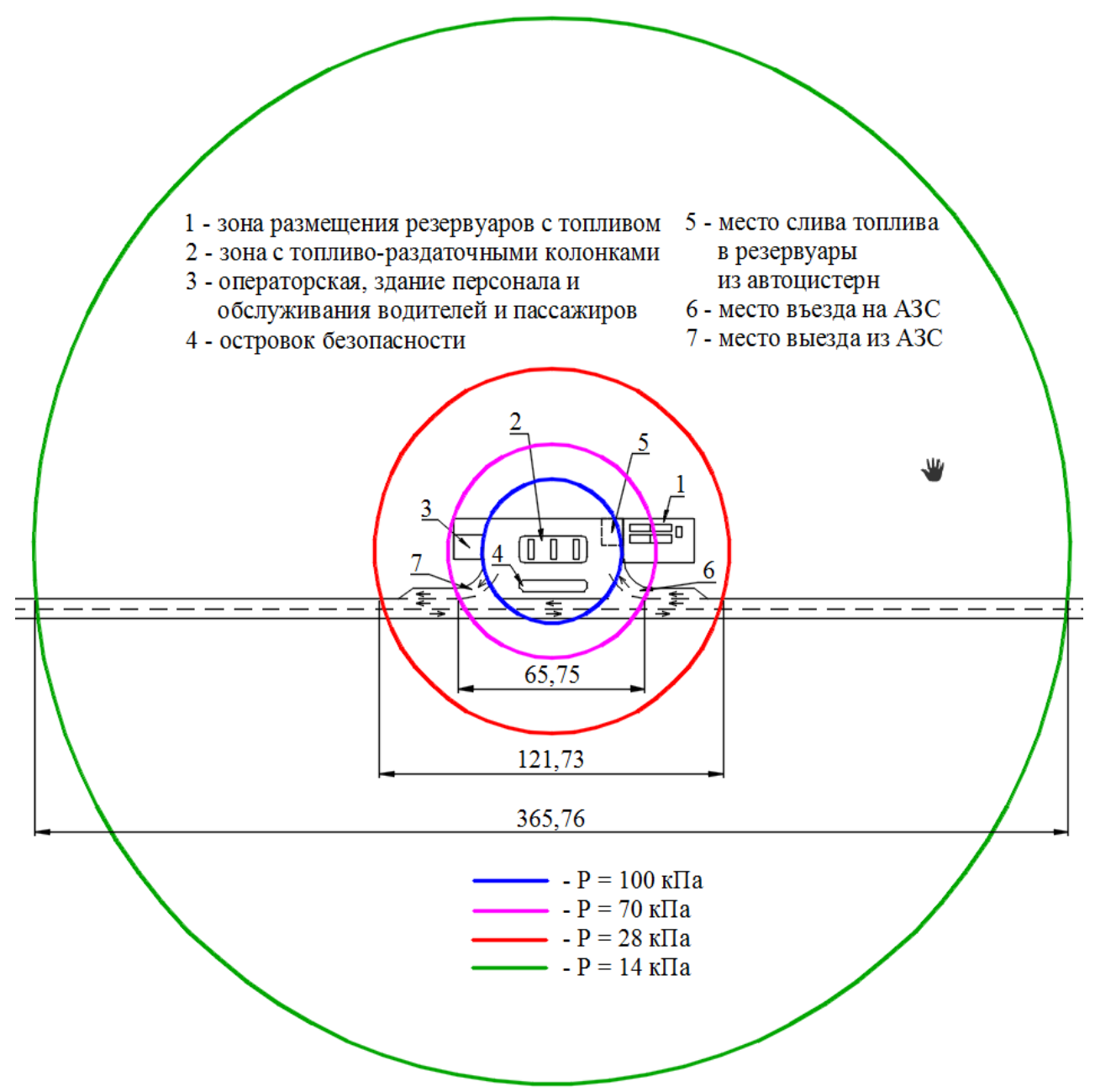

Рисунок 3. Поражающие факторы взрыва облака топливовоздушной смеси на открытом пространстве на АЗС средней мощности при разливе бензина А-95 с топливораздаточной колонки.

Радиус распространения ударной волны уместно определять для избыточного давления: 14кПа - как границу легких травм для человека и повреждений материальных объектов. Автомобиль в этой зоне может сдвинуться в горизонтальной плоскости, могут быть также выбиты стекла; 28 кПа - как границу средних травм и повреждений, транспортное средство может быть опрокинуто, обязательно, разобьются окна; 70 кПа - тяжелых травм и повреждений, автомобиль может отбросить ударной волной и перевернуть, с тяжелыми последствиями для 
пассажиров и водителя. Длина опасного участка была рассчитана для различных радиусов распространения ударной волны и расстояния от эпицентра взрыва до и результаты приведены в таблице 4.

Расстояние на дороге где возможно возникновение избыточного давления взрывной волны определяется по формуле:

$$
a=2 \sqrt{R^{2}-l^{2}}
$$

где $R$ - радиус распространения ударной волны, м;

$l$ - расстояние от эпицентра взрыва до проезжей части, м.

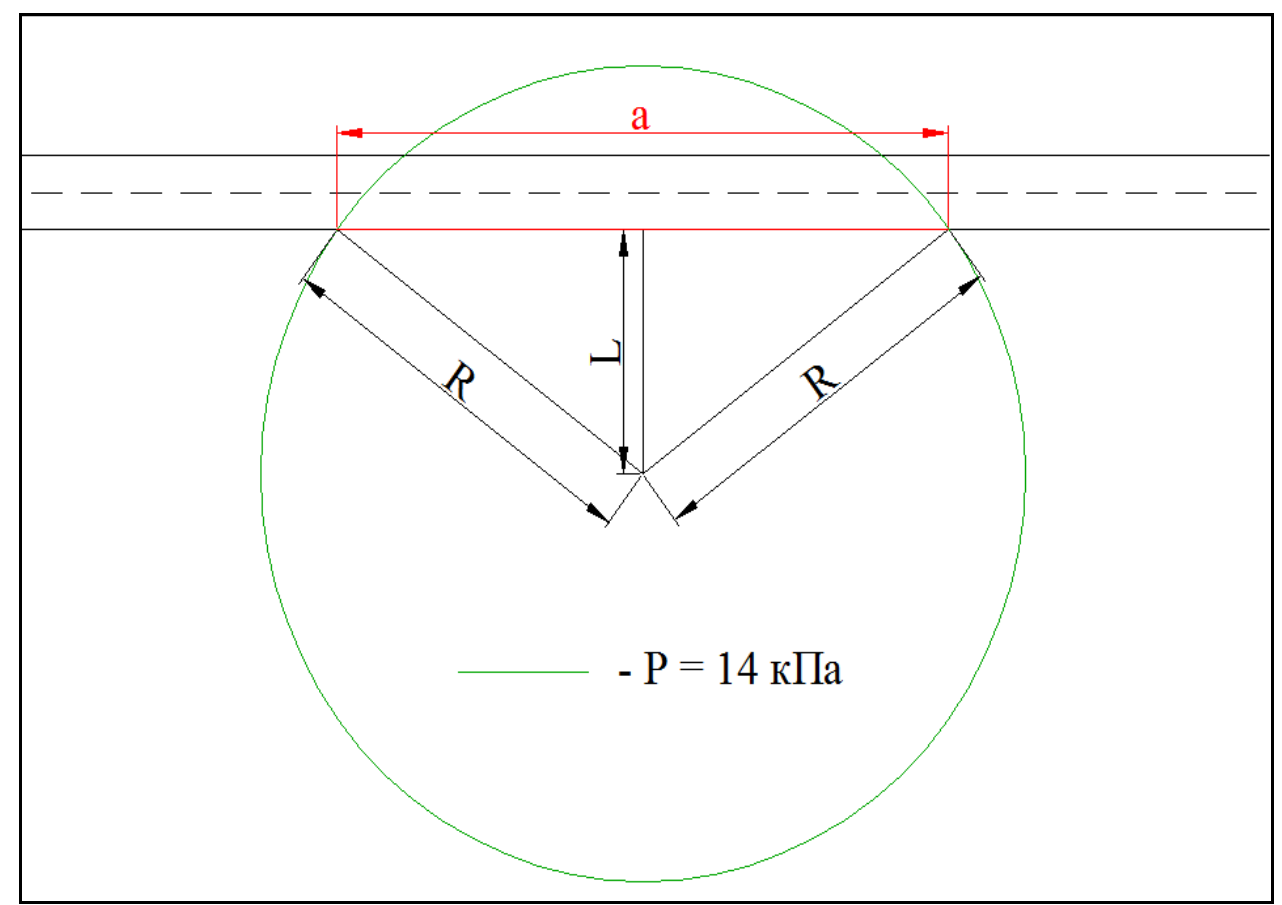

Рисунок 4. Схема определения опасного участка автомобильной дороги. 
Таблица 4. Длина опасного участка автомобильной дороги

\begin{tabular}{|c|c|c|c|c|c|c|c|c|c|c|c|c|c|}
\hline \multirow{2}{*}{$\begin{array}{c}\text { Радиус } \\
\text { распространения } \\
\text { ударной волны, } \\
\text { м }\end{array}$} & \multicolumn{13}{|c|}{ Расстояние от эпицентра взрыва до проезжей части, м } \\
\hline & 10 & 20 & 40 & 60 & 80 & 100 & 120 & 140 & 160 & 180 & 200 & 220 & 240 \\
\hline 10 & 0 & - & - & - & - & - & - & - & - & - & - & - & - \\
\hline 20 & 35 & 0 & - & - & - & - & - & - & \multicolumn{5}{|c|}{70 кПа } \\
\hline 40 & 77 & 69 & 0 & - & - & - & - & - & - & - & - & - & - \\
\hline 60 & 118 & 113 & 89 & 0 & - & - & - & - & - & - & - & - & - \\
\hline 80 & 159 & 155 & 139 & 106 & 0 & - & - & - & - & - & - & - & - \\
\hline 100 & 199 & 196 & 183 & 160 & 120 & 0 & - & - & - & \multicolumn{4}{|c|}{28 кПа } \\
\hline 120 & 239 & 237 & 226 & 208 & 179 & 133 & 0 & - & - & - & - & - & - \\
\hline 140 & 279 & 277 & 268 & 253 & 230 & 196 & 144 & 0 & - & - & - & - & - \\
\hline 160 & 319 & 317 & 310 & 297 & 277 & 250 & 212 & 155 & 0 & - & \multicolumn{3}{|c|}{14 кПа } \\
\hline 180 & 359 & 358 & 351 & 339 & 322 & 299 & 268 & 226 & 560 & 0 & - & - & - \\
\hline 200 & 399 & 398 & 392 & 382 & 367 & 346 & 320 & 286 & 660 & 174 & 0 & - & - \\
\hline 220 & 440 & 438 & 433 & 423 & 410 & 392 & 369 & 339 & 755 & 253 & 183 & 0 & - \\
\hline 240 & 480 & 478 & 473 & 465 & 453 & 436 & 416 & 390 & 847 & 317 & 265 & 192 & 0 \\
\hline
\end{tabular}

В таблице 5 рассчитано количество автомобилей, которые могут оказаться в опасной зоне при расположении АЗС на расстоянии 20 м от края проезжей части.

Таблица 5. Количество автомобилей, которые в случае возникновения аварийной ситуации на АЗС, будут находиться в опасной зоне

\begin{tabular}{|c|c|c|c|c|c|c|c|c|c|c|c|c|}
\hline \multirow{3}{*}{$\mathrm{a}, \mathrm{m}$} & \multicolumn{4}{|c|}{$\mathrm{t}, \mathrm{c}$} & \multicolumn{4}{|c|}{ tcep., c } & \multicolumn{4}{|c|}{ К, автомобилей } \\
\hline & \multirow{2}{*}{$\begin{array}{c}\text { I } \\
\text { кат }\end{array}$} & \multirow{2}{*}{$\begin{array}{c}\text { II } \\
\text { кат }\end{array}$} & \multirow{2}{*}{$\begin{array}{c}\text { III } \\
\text { кат }\end{array}$} & \multirow{2}{*}{$\begin{array}{c}\text { VI } \\
\text { кат }\end{array}$} & I кат & II кат & III кат & VI кат & I кат & $\begin{array}{c}\text { II } \\
\text { кат }\end{array}$ & $\begin{array}{c}\text { III } \\
\text { кат }\end{array}$ & $\begin{array}{c}\text { VI } \\
\text { кат }\end{array}$ \\
\hline & & & & & 10000 & 3000 & 1000 & 150 & 10000 & 3000 & 1000 & 150 \\
\hline \multicolumn{13}{|c|}{70 кПа } \\
\hline 50 & 2 & 2 & 2 & 2 & 3,60 & 12,00 & 36,00 & 240,00 & 0,58 & 0,18 & 0,06 & 0,01 \\
\hline 100 & 4 & 4 & 5 & 5 & 3,60 & 12,00 & 36,00 & 240,00 & 1,16 & 0,36 & 0,13 & 0,02 \\
\hline \multicolumn{13}{|c|}{28 кПа } \\
\hline 150 & 6 & 7 & 7 & 7 & 3,60 & 12,00 & 36,00 & 240,00 & 1,74 & 0,54 & 0,19 & 0,03 \\
\hline 200 & 8 & 9 & 9 & 10 & 3,60 & 12,00 & 36,00 & 240,00 & 2,31 & 0,72 & 0,25 & 0,04 \\
\hline 250 & 10 & 11 & 11 & 12 & 3,60 & 12,00 & 36,00 & 240,00 & 2,89 & 0,91 & 0,32 & 0,05 \\
\hline \multicolumn{13}{|c|}{14 кПа } \\
\hline 300 & 13 & 13 & 14 & 14 & 3,60 & 12,00 & 36,00 & 240,00 & 3,47 & 1,09 & 0,38 & 0,06 \\
\hline 350 & 15 & 15 & 16 & 17 & 3,60 & 12,00 & 36,00 & 240,00 & 4,05 & 1,27 & 0,44 & 0,07 \\
\hline 400 & 17 & 17 & 18 & 19 & 3,60 & 12,00 & 36,00 & 240,00 & 4,63 & 1,45 & 0,51 & 0,08 \\
\hline 450 & 19 & 20 & 20 & 21 & 3,60 & 12,00 & 36,00 & 240,00 & 5,21 & 1,63 & 0,57 & 0,09 \\
\hline 500 & 21 & 22 & 23 & 24 & 3,60 & 12,00 & 36,00 & 240,00 & 5,79 & 1,81 & 0,63 & 0,10 \\
\hline
\end{tabular}

По крайней мере 1 автомобиль может попасть в зону легких травм и повреждений уже при интенсивности движения до 2000 авт / сут. В зону средних 
травм и повреждений - при интенсивности движения от 3500 до 6000 авт / сут. В зону тяжелых последствий - при интенсивности движения 9000 авт / сут.

Вероятность того, что на дороге VI-й категории, по крайней мере, один автомобиль попадет в зону поражения ударной волны, не превышает 0,6.

На дороге III-й категории вероятность попадания хотя бы 1 автомобиля в зону тяжелых и средних повреждений составит 0,8 . В зону легких повреждений может попасть до 2-х автомобилей.

Существует вероятность на дороге II-й категории, что в зону тяжелых поражений попадет один автомобиль, в зону средних - до 2-х автомобилей, в зону легких - 3-4 автомобиля.

На дороге І-й категории (интенсивность движения 10000 авт / сут) в зоне легких травм и повреждений может оказаться от 3-х до 6 автомобилей; средних - 2-3 автомобиля; тяжелых - не менее, чем 1 автомобиль.

\section{ВЫВОДЫ}

Итак, чтобы избежать тяжелых последствий аварии автозаправочная станция должна находиться на безопасном расстоянии от автомобильной дороги и застройки. За безопасное расстояние можно принять радиус действия избыточного давления взрывной волны равный 28 кПа. АЗС в данном случае должна размещаться на расстоянии 45 м от дороги, а административное здание станции как минимум в 27м от топливно-раздаточных колонок и узла слива горючего в резервуары.

Руководствуясь приведенными выше данными, можно сказать, что комплексы (АЗК), которые включают в себя площадки отдыха, рестораны, гостиницы и прочее, расположенные рядом с АЗС, в случае взрыва попадают в зону сильных разрушений и тяжелых травм. Поэтому проектировать такие комплексы нужно с учетом вида топлива, максимально возможного разлива и, соответственно, безопасного расстояния.

\section{ЛИТЕРАТУРА}

[1] А.Н. Бандурка, И.К. Шаша, И.В. Власенко, П.Н. Бортничук, Охрана труда в деятельности ОВД Украины:: Учебник, Изд-во Нац. ун-та внутр. дел, Москва 2003.

[2] Стеблюк М.И., Гражданская оборона и гражданская защита: Учебник, 2-е изд., Перераб., Москва 2010.

[3] НАПБ Б.03.002-2007, Нормы определения категорий помещений, зданий и наружных установок по взрывопожарной и пожарной опасности, Киев 2007.

[4] Методика определения рисков и их приемлемых уровней для декларирования безопасности объектов повышенной опасности утвержден приказом Министерства труда и социальной политики Украины от 04.12.2002, N 637.

[5] ДБН 360-92 **, Градостроительство. Планировка и застройка городских и сельских поселений.

[6] ДБН В.2.3-4: 2007. Автомобильные дороги.

[7] Закон України № 2245-III від 18.01.2001р. “Про об’ єкти підвищеної небезпеки”.

[8] Постанова Кабінету Міністрів України № 956 від 11.07.2002 р. "Порядок ідентифікації та обліку об' єктів підвищеної небезпеки".

[9] Захист населення і територій від надзвичайних ситуачій, Т. 1, Техногенна та природна небезпека / За загальною редакиією В.В. Могильниченка, КІМ, Киев 2007. 
[10] Взрывные явления. Оценка последствия: В2-х кн. Кн. 1 Пер. 3 англ./Бейкер У. И др.; под ред. Я. Б. Зельдовича, Б. Є. Гельфанда, Мир, Москва 1986.

[11] Борисов А.А., Гельфанд Б.С., Цыганов С.А. (Москва), О моделировании волн давления, образуюшиеся при детонаиии горении газовых смесей, „Физика горения и взрыва” $1985 / 2$.

[12] Методична розробка для проведення семінарського заняття. Поняття про вибух. Вплив вибуху на будівлі та споруди. Вибухозахист, http://dspace.univer.kharkov.ua/bitstream/ $123456789 / 7629 / 2 / \% \mathrm{D} 0 \% 9 \mathrm{C} \% \mathrm{D} 0 \% 95 \% \mathrm{D} 0 \% \mathrm{~A} 2 \% \mathrm{D} 0 \% 9 \mathrm{E} \% \mathrm{D} 0 \% 94 \% \mathrm{D} 0 \% 98 \% \mathrm{D} 0 \% \mathrm{~A} 7 \% \mathrm{D} 0$ \%9A\%D0\%90\%202\%20\%D0\%A6\%D0\%97.pdf Дата звернення (6.11.2014).

\section{RISKS OF FINDING CARS ON THE ROAD IN AN AREA OF PETROL STATIONS. PLACEMENT RECOMMENDATION PETROL STATION}

One of the most important components of an integrated service on the roads is a petrol station. Petrol stations are assigned to objects that represent increased risk. This risk is associated with the effects of the activities of the gas station and accidents on them. On road sections where the gas station, the concentration of harmful emissions into the atmosphere is increasing dramatically. In the event of an accident (eg, explosion) pollution can reach far beyond the critical standards, as it will delay traffic on the road, destruction facilities and as a result of large economic losses to eliminate the consequences of the accident. Today, placement of gas stations do not take into account the possible emergencies that can occur when flammable substances can get from the hardware into the environment and pose a real risk of fires and explosions fuel-air mixtures. The main parameter determining a safe distance from the gas station is its explosiveness. In the event of an accident at the station of explosion spilled fuel vapor overpressure blast, in the area of buildings, structures and vehicles may experience a strong and medium damage and cause injury to people. The consequences of such an accident will depend on the number of vehicles, buildings and, consequently, people caught in the affected area, as well as the force of the explosion. Therefore, the question of safety distances to the road and crowded places still open and sharp.

Keywords: Gas station explosion, the shock wave, overpressure, blast wave.

DOI: 10.7862/rz.2015.mmr.28

Tekst złożono w redakcji: kwiecień 2015

Przyjęto do druku: czerwiec 2015 